\title{
Adipose tissue area as a predictor for the efficacy of apatinib in platinum-resistant ovarian cancer: an exploratory imaging biomarker analysis of the AEROC trial
}

Xin Huang ${ }^{1 \dagger}$, Chuanbo Xie ${ }^{2 \dagger}$, Jie Tang ${ }^{3 \dagger}$, Wenzhuo He ${ }^{4 \dagger}$, Fan Yang ${ }^{1+}$, Wenfang Tian ${ }^{3}$, Jundong Li ${ }^{1}$, Qiuxia Yang ${ }^{5}$, Jingxian Shen ${ }^{5}$, Liangping $\mathrm{Xia}^{4^{*}}$ and Chunyan $\operatorname{Lan}^{1^{*}}$ (D)

\begin{abstract}
Background: Vascular endothelial growth factor (VEGF)-targeted therapy is effective in patients with ovarian cancer. Whether adipose tissue (AT) could predict the efficacy of VEGF receptor (VEGFR) inhibitors in ovarian cancer is unknown. We aimed to evaluate the ability of distinct AT depots to predict the efficacy of apatinib, a VEGFR inhibitor, in recurrent ovarian cancers included in the AEROC trial.

Methods: The AEROC was a single-arm phase 2 trial of apatinib and oral etoposide in patients with platinumresistant or platinum-refractory ovarian cancer. Apatinib was administered continuously, and oral etoposide was administered every 21 days for a maximum of six cycles. This was a post hoc study based on the AEROC trial. Areas of visceral AT (VAT), subcutaneous AT (SAT), and intermuscular AT (IMAT) were measured using computed tomography scan at baseline to assess their association with the objective response rate, progression-free survival, and overall survival.

Results: Of the 35 treated patients, 31 patients with at least one post-baseline efficacy assessment by computed tomography scan were included in this study. After adjusting for apatinib exposure, high VAT (odds ratio [OR], 0.16; $95 \%$ confidence interval $[\mathrm{Cl}], 0.03-0.90, P=0.037)$ and $\mathrm{SAT}(\mathrm{OR}, 0.16 ; 95 \% \mathrm{Cl}, 0.03-0.87, P=0.034)$ were significantly associated with a higher objective response rate. Further, decreased risks of disease progression and death were associated with high VAT (hazard ratio [HR], 0.39; 95\% Cl, 0.17-0.92, $P=0.031$, and $\mathrm{HR}, 0.12 ; 95 \% \mathrm{Cl}, 0.04-0.40, P<$ 0.001 , respectively), SAT (HR, 0.35; 95\% Cl, 0.15-0.83, $P=0.027$, and $\mathrm{HR}, 0.24 ; 95 \% \mathrm{Cl}, 0.08-0.67, P=0.007$,

(Continued on next page)
\end{abstract}

\footnotetext{
* Correspondence: xialp@sysucc.org.cn; lanchy@sysucc.org.cn

${ }^{+}$Xin Huang, Chuanbo Xie, Jie Tang, Wenzhuo He and Fan Yang contributed equally to this work.

${ }^{4}$ VIP Region, Sun Yat-sen University Cancer Centre, State Key Laboratory of Oncology in South China, Collaborative Innovation Center for Cancer Medicine, 651 Dongfeng Road East, Guangzhou 510060, Guangdong, China 'Department of Gynecologic Oncology, Sun Yat-sen University Cancer Centre, State Key Laboratory of Oncology in South China, Collaborative Innovation Center for Cancer Medicine, 651 Dongfeng Road East, Guangzhou 510060, Guangdong, China

Full list of author information is available at the end of the article
}

C The Author(s). 2020 Open Access This article is licensed under a Creative Commons Attribution 4.0 International License, which permits use, sharing, adaptation, distribution and reproduction in any medium or format, as long as you give appropriate credit to the original author(s) and the source, provide a link to the Creative Commons licence, and indicate if changes were made. The images or other third party material in this article are included in the article's Creative Commons licence, unless indicated otherwise in a credit line to the material. If material is not included in the article's Creative Commons licence and your intended use is not permitted by statutory regulation or exceeds the permitted use, you will need to obtain permission directly from the copyright holder. To view a copy of this licence, visit http://creativecommons.org/licenses/by/4.0/ The Creative Commons Public Domain Dedication waiver (http://creativecommons.org/publicdomain/zero/1.0/) applies to the data made available in this article, unless otherwise stated in a credit line to the data. 


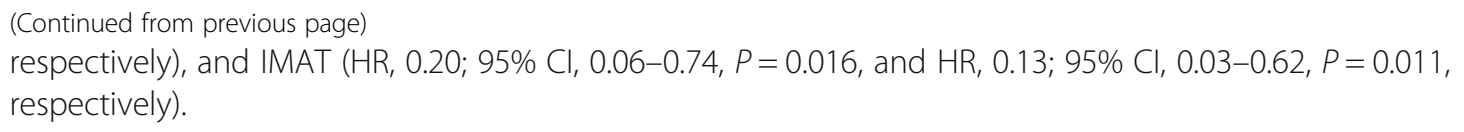

Conclusions: High areas of VAT, SAT, and IMAT were significantly associated with better outcomes in patients with platinum-resistant or platinum-refractory ovarian cancer who received VEGFR inhibitors. AT assessments may be valuable as patient-specific imaging biomarkers for predicting response to VEGFR inhibitors.

Trial registration: ClinicalTrials.gov identifier: NCT02867956.

Keywords: Ovarian cancer, Visceral adipose tissue, Subcutaneous adipose tissue, Intermuscular adipose tissue, Vascular endothelial growth factor receptor

\section{Background}

Ovarian cancer is the deadliest gynecologic malignancy and fifth most common cause of cancer mortality in women in developed countries [1]. Angiogenesis plays an important role in the natural history of ovarian cancer, promoting tumor growth and progression [2, 3]. The vascular endothelial growth factor (VEGF) signaling pathway is the most widely studied angiogenic pathway in ovarian cancer. The addition of anti-angiogenic drugs to chemotherapy, including VEGF receptor (VEGFR) tyrosine kinase inhibitors (TKIs), has shown clinical benefit in terms of progression-free survival (PFS) in patients with ovarian cancer, both in the upfront and recurrent settings [4, 5]. However, as not all patients benefit from anti-angiogenic therapy, identification of predictive biomarkers can help with the selection of patients responsive to this treatment. There is currently a lack of reliable and validated biomarkers for predicting the outcome of patients with ovarian cancer who receive VEGFR TKIs.

Obesity represents the excess accumulation of fat in adipose tissue (AT) and is known to increase the risk for quite diverse types of cancers [6, 7], including endometrial cancer, colorectal cancer, breast cancer, prostate cancer, and pancreatic cancer. It is also associated with higher risks of recurrence after treatment and death in many cancer types $[8,9]$. The mechanisms linking excess AT and cancer development are not well understood, but obesity-associated chronic inflammation is widely accepted as an important factor in carcinogenesis $[10,11]$. Moreover, it has been demonstrated that activated adipocytes produce multiple angiogenic factors, including VEGF, leptin, fibroblast growth factor-2 (FGF-2), tumor growth factor $\beta$ (TGF- $\beta$ ), and placental growth factor (PGF), which stimulate neovascularization during AT expansion [12-14]. Indeed, adipogenesis is closely associated with angiogenesis [14]. Recently, several studies demonstrated that the areas of visceral AT (VAT) or subcutaneous AT (SAT) measured by computed tomography (CT) may predict the outcome of patients with metastatic colorectal cancer [15], renal cell cancer [16, 17], and melanoma [18], who were treated with VEGF-targeted therapy. However, these results were controversial.

Apatinib is a small molecule TKI that selectively inhibits VEGFR2. Previously, we reported the outcomes of a single-arm, phase 2 study (AEROC) on the efficacy of apatinib combined with oral etoposide in patients with platinum-resistant or platinum-refractory ovarian cancer [19]. The combination of apatinib and oral etoposide showed promising activity in this setting. In the current study, we evaluated the areas of VAT, SAT, and intermuscular AT (IMAT) using CT images that were collected prospectively in the AEROC trial. We analyzed the associations between $\mathrm{AT}$ areas and patient outcomes to evaluate whether distinct AT depots could predict the efficacy of apatinib in patients with platinum-resistant ovarian cancer.

\section{Methods}

Study design

The AEROC trial was a phase 2, single-arm, prospective study in patients with platinum-resistant or platinumrefractory ovarian cancer; the design and results have been previously reported [18]. In brief, the AEROC trial evaluated the efficacy and safety of apatinib and oral etoposide in patients with platinum-resistant or platinumrefractory ovarian cancer who had been treated with at least one line of platinum-based chemotherapy. The patients were treated with apatinib at an initial dose of $500 \mathrm{mg}$ daily on a continuous basis and oral etoposide $50 \mathrm{mg}$ once daily on days 1-14 of a 21-day cycle, for a maximum of six cycles. The primary endpoint was the objective response rate (ORR) using the Response Evaluation Criteria In Solid Tumors (RECIST) version 1.1. PFS and overall survival (OS) were the two main secondary endpoints.

As per protocol, dose modification, including dose interruptions and dose reductions, was performed based on the severity of toxicities according to NCI Common Terminology for Adverse Events (CTCAE), version 4.03 grading system. A maximum of two dose reductions were allowed for apatinib. The first dose reduction was 
from $500 \mathrm{mg}$ once per day continuously to $500 \mathrm{mg}$ and $250 \mathrm{mg}$ taken on alternate days, and the additional dose reduction was to $250 \mathrm{mg}$ once daily. If the apatinib dose was reduced, the dose could not be increased later. General guidelines for apatinib dose modification were presented in the protocol (Additional file 11: study protocol). The proportion of patients who had apatinib dose reduction and the reasons for apatinib dose reductions had been described previously [19].

The present study was a post hoc, secondary analysis of the AEROC trial. The primary objective was to evaluate the predictive value of VAT, SAT, and IMAT for the efficacy of apatinib-based treatment. The associations between areas of AT depots and ORR, updated PFS, and updated OS were investigated.

Informed consent was obtained from all patients. Ethical approval was obtained by the institutional review board of Sun Yat-sen University Cancer Centre. The procedures were in accordance with the ethical standards.

\section{$\mathrm{CT}$ analysis}

All patients underwent CT scans before the initiation of treatment for the purpose of efficacy assessment. CT examinations were performed on a clinical 64-slice CT scanner Discovery CT750 HD (GE Medical Systems; GE, Waukesha, USA), a Dual Source CT scanner (SOMATOM Force; SIEMENS, Erlangen, Germany), and iCT 256 (PHILIPS, Cleveland, USA). A single slice of each patient's baseline CT image at the third lumbar vertebra (L3) was selected and analyzed by experienced radiologists blinded to patient information. The threshold was set between -190 and -30 Hounsfield units (HU) [20, 21 , which is the attenuation range of AT on CT images. The VAT area was defined as intraabdominal fat bound by the parietal peritoneum or transversalis fascia, excluding the vertebral column and paraspinal muscles, with a density between -150 and $-50 \mathrm{HU}$ [20]. The SAT area was defined as the fat superficial to the abdominal and back muscles with attenuation ranging from -190 to $30 \mathrm{HU}$. The IMAT area was defined as the AT area visible between muscle groups and beneath the muscle fascia with attenuation ranging from -190 to $-30 \mathrm{HU}$. The cross-sectional surface areas $\left(\mathrm{cm}^{2}\right)$ of VAT, SAT, and IMAT were calculated automatically using the semiautomated GE Reformat post-processing tool (Centricity Radiology RA1000; GE Medical Healthcare, Little Chalfont, UK). Representative axial CT images with respect to VAT, SAT, and IMAT are shown in Fig. 1.

\section{Statistical analyses}

We used optimum stratification to define the optimal cutoffs for the areas of VAT, SAT, and IMAT [22]. Optimum stratification by $\mathrm{SAS}^{\circ}$ macros solves the threshold value of continuous covariates with binary outcomes (SAS ${ }^{\circ}$ macros \%cutpoint) and time-to-event outcomes $\left(\mathrm{SAS}^{\circ}\right.$ macros \%findcut) [22]. Therefore, the cutoffs for the areas of VAT, SAT, and IMAT to assess association with the ORR were determined using $\mathrm{SAS}^{\circ}$ macros \%cutpoint, and the cutoffs to assess association with PFS and OS were determined using $\mathrm{SAS}^{\circ}$ macros \% findcut. If more than one cutoff was suggested, the value that best distinguished patients with respect to ORR, PFS, and OS was selected. These cutoffs were then used to classify patients as having high and low VAT, SAT, and IMAT.

The distributions of patient characteristics according to the areas of VAT, SAT, and IMAT were compared using the chi-square or Fisher's exact tests for categorical variables and independent $t$ test for continuous variables. The relationships between the ORR and the areas of VAT, SAT, and IMAT were assessed using logistic regressions and adjusted for the dosage of apatinib. The Kaplan-Meier curves were used to display survival distributions, and the log-rank test was used to assess the difference between patients with high and low areas of AT depots. Hazard ratios (HRs) and corresponding 95\% confidence intervals (CIs) for risk of disease progression and mortality associated with high and low areas of AT depots were estimated using Cox proportional hazards models. Multivariate Cox models were adjusted for the dosage of apatinib. All statistical analyses were performed using SAS version 9.4 (SAS Institute Inc., Cary, NC, USA). All tests were two-sided, and the significance level was set as 0.05 .

\section{Results}

Patients

From August 10, 2016, to November 9, 2017, a total of 35 patients were enrolled in the AEROC trial. All 35 patients had baseline CT images. Four patients did not have post-baseline efficacy evaluation and were excluded from the current study. Thus, 31 patients with at least one post-baseline efficacy assessment by CT scan were included in this study. The data cutoff date used for the present analysis was February 7, 2019. The median follow-up was 13.8 months (range, 4.4-25.4 months). As of the data cutoff date, 2 patients were still receiving apatinib.

\section{Optimal cutoffs for the areas of VAT, SAT, and IMAT}

An area of $55.53 \mathrm{~cm}^{2}$ was selected as the optimal cutoff for VAT associated with the ORR (Additional file 1: Table S1), PFS (Additional file 2: Fig. S1), and OS (Additional file 3: Fig. S2). The optimal cutoff for the area of SAT associated with ORR (Additional file 4: Table S2), PFS (Additional file 5: Fig. S3), and OS (Additional file 6: Fig. S4) was $129.28 \mathrm{~cm}^{2}$, and $3.28 \mathrm{~cm}^{2}$ was selected as 
a

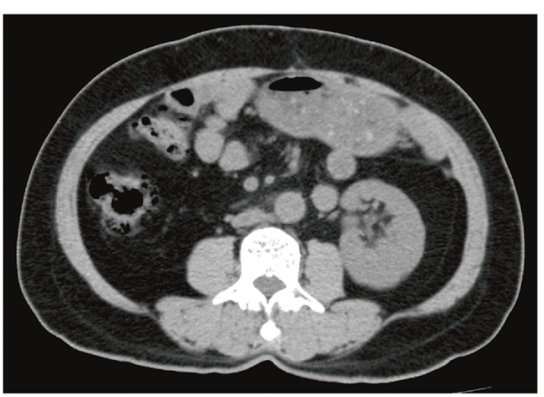

c

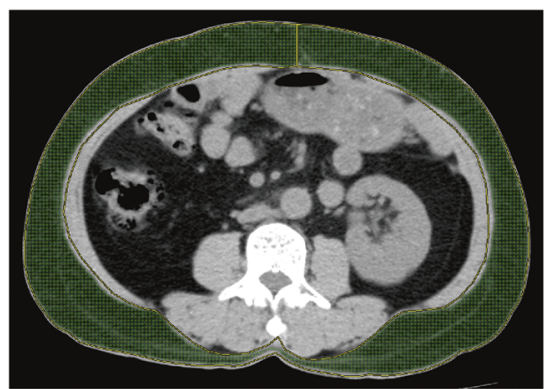

b

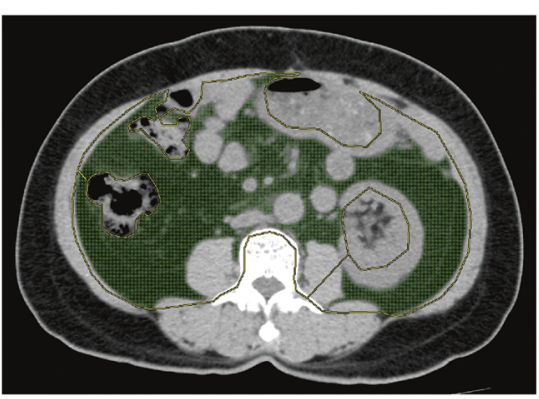

d

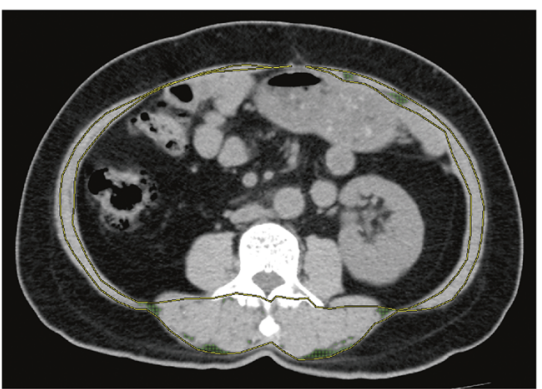

Fig. 1 Representative axial CT images with respect to VAT, SAT, and IMAT. a The original CT image of AT and the segmentation of $\mathbf{b}$ VAT, $\mathbf{c}$ SAT, and $\mathbf{d}$ IMAT. CT, computed tomography; AT, adipose tissue; VAT, visceral AT; SAT, subcutaneous AT; IMAT, intermuscular AT

the optimal cutoff for the area of IMAT associated with ORR (Additional file 7: Table S3), PFS (Additional file 8: Fig. S5), and OS (Additional file 9: Fig. S6). Patients with an area below these values were classified as having low VAT, SAT, and IMAT, respectively, and patients with an area above these values were classified as having high VAT, SAT, and IMAT, respectively. Representative axial CT images of two patients were provided (Additional file 10: Fig. S7): one with low VAT, low SAT, and low IMAT, and the other with high VAT, high SAT, and high IMAT.

\section{Patient characteristics according to areas of VAT, SAT, and IMAT}

Patient characteristics according to VAT, SAT, and IMAT depots are summarized in Table 1 . No significant differences in the majority of patient characteristics were observed between patients with high or low VAT, SAT, or IMAT. However, patients with high VAT $(P=0.049)$ and high SAT $(P=0.034)$ had significantly higher apatinib exposure (Table 1). Apatinib exposure was higher among patients with high IMAT than among patients with low IMAT, and the difference approached but did not reach significance $(P=0.096$, Table 1$)$.

\section{Association of AT depots with ORR}

In univariate logistic regression, high VAT $(P=0.015)$ and high SAT $(P=0.015)$ were significantly associated with a higher ORR (Table 2). High IMAT was marginally associated with a higher ORR $(P=0.066)$. After adjusting for the dosage of apatinib, high VAT (odds ratio [OR], 0.16; 95\% CI, 0.03-0.90, $P=0.037$ ) and high SAT (OR, 0.16; 95\% CI, 0.03-0.87, $P=0.034$ ) were still associated with a higher ORR. However, the association between IMAT and response to apatinib was not significant when controlling for apatinib exposure (Table 2).

\section{Association of AT depots with PFS}

Univariate analysis demonstrated that patients with high VAT (Fig. 2a), high SAT (Fig. 3a), and high IMAT (Fig. 4a) were associated with a lower risk of disease progression than those with low VAT $(P=0.035)$, low SAT $(P=0.028)$, and low IMAT $(P=0.005)$, respectively. When adjusting for the dosage of apatinib (Table 3), high VAT was associated with a $61 \%(\mathrm{HR}, 0.39 ; 95 \% \mathrm{CI}$, $0.17-0.92, P=0.031)$ lower risk of disease progression compared with low VAT. High SAT and high IMAT were associated with a $65 \%$ and an $80 \%$ decreased risk of disease progression, respectively.

\section{Association of AT depots with OS}

Univariate analysis showed a lower risk for death among patients with high VAT (Fig. 2b), high SAT (Fig. 3b), and high IMAT (Fig. 4b) than patients with low VAT, low SAT, and low IMAT, respectively. With adjustment for the dosage of apatinib (Table 3), high VAT, high SAT, and high IMAT were associated with an $88 \%$ (HR, 0.12; 95\% CI, 0.04-0.40, $P<0.001$ ), a 76\% (HR, 0.24; 95\% CI, $0.08-0.67, P=0.007$ ), and an $87 \%$ (HR, 0.13 ; $95 \% \mathrm{CI}$, 
Table 1 Patient characteristics according to VAT, SAT, and IMAT areas

\begin{tabular}{|c|c|c|c|c|c|c|c|c|c|c|}
\hline \multirow[t]{2}{*}{ Characteristic } & \multirow[t]{2}{*}{ All $(N=31)$} & \multicolumn{2}{|l|}{ VAT } & \multirow{2}{*}{$\begin{array}{l}P \\
\text { value }\end{array}$} & \multicolumn{2}{|l|}{ SAT } & \multirow{2}{*}{$\begin{array}{l}P \\
\text { value }\end{array}$} & \multicolumn{2}{|l|}{ IMAT } & \multirow{2}{*}{$\begin{array}{l}P \\
\text { value }\end{array}$} \\
\hline & & $\begin{array}{l}\text { Low }(N= \\
12)\end{array}$ & $\begin{array}{l}\text { High }(N= \\
19)\end{array}$ & & $\begin{array}{l}\text { Low }(N= \\
12)\end{array}$ & $\begin{array}{l}\operatorname{High}(N= \\
19)\end{array}$ & & Low $(N=5)$ & $\begin{array}{l}\operatorname{High}(N= \\
26)\end{array}$ & \\
\hline \multicolumn{4}{|l|}{ Age, N (\%) } & 0.842 & & & 0.842 & & & $0.133^{*}$ \\
\hline$<60$ years & $20(64.5)$ & $8(66.7)$ & $12(63.2)$ & & $8(66.7)$ & $12(63.2)$ & & $5(100)$ & $15(57.7)$ & \\
\hline$\geq 60$ years & $11(35.5)$ & $4(33.3)$ & $7(36.8)$ & & $4(33.3)$ & $7(36.8)$ & & $0(0)$ & $11(42.3)$ & \\
\hline \multicolumn{4}{|l|}{ Histology at diagnosis, N (\%) } & $0.917^{*}$ & & & $0.917^{*}$ & & & $1.000^{*}$ \\
\hline $\begin{array}{l}\text { High-grade serous } \\
\text { carcinoma }\end{array}$ & $24(77.4)$ & $9(75.0)$ & $15(78.9)$ & & $9(75.0)$ & $15(78.9)$ & & $5(100)$ & $19(73.1)$ & \\
\hline $\begin{array}{l}\text { Low-grade serous } \\
\text { carcinoma }\end{array}$ & $1(3.2)$ & $0(0)$ & $1(5.3)$ & & $0(0)$ & $1(5.3)$ & & $0(0)$ & $1(3.8)$ & \\
\hline Endometrioid & $2(6.5)$ & $1(8.3)$ & $1(5.3)$ & & $1(8.3)$ & $1(5.3)$ & & $0(0)$ & $2(7.7)$ & \\
\hline Clear cell & $3(9.7)$ & $1(8.3)$ & $2(10.5)$ & & $1(8.3)$ & $2(10.5)$ & & $0(0)$ & $3(11.5)$ & \\
\hline Mucinous & $1(3.2)$ & $1(8.3)$ & $0(0)$ & & $1(8.3)$ & $0(0)$ & & $0(0)$ & $1(3.8)$ & \\
\hline \multicolumn{4}{|l|}{ ECOG performance status, $N(\%)$} & $0.644^{*}$ & & & $0.644^{*}$ & & & $0.656^{*}$ \\
\hline 0 & $8(25.8)$ & $2(16.7)$ & $6(31.6)$ & & $2(16.7)$ & $6(31.6)$ & & $2(40)$ & $6(23.1)$ & \\
\hline 1 & $22(71.0)$ & 10 (83.3) & $12(63.2)$ & & 10 (83.3) & $12(63.2)$ & & $3(60)$ & 19 (73.1) & \\
\hline 2 & $1(3.2)$ & $0(0)$ & $1(5.3)$ & & $0(0)$ & $1(5.3)$ & & $0(0)$ & $1(3.8)$ & \\
\hline \multicolumn{4}{|c|}{$\begin{array}{l}\text { Number of previous chemotherapy lines, } N \\
(\%)\end{array}$} & 0.763 & & & 1.000 & & & $0.800^{*}$ \\
\hline 1-2 lines & $7(22.6)$ & $3(25)$ & $4(21.1)$ & & $3(25)$ & $4(21.1)$ & & $1(20)$ & $6(23.1)$ & \\
\hline $3-6$ lines & 19 (61.3) & $8(66.7)$ & 11 (57.9) & & $7(58.3)$ & 12 (63.2) & & $4(80)$ & $15(57.7)$ & \\
\hline$>6$ lines & $5(16.1)$ & $1(8.3)$ & $4(21.1)$ & & $2(16.7)$ & $3(15.8)$ & & $0(0)$ & $5(19.2)$ & \\
\hline \multicolumn{7}{|c|}{ Interval between last chemotherapy and disease progression, $N(\%)$} & 0.676 & & & $0.562^{*}$ \\
\hline$<3$ months & $24(77.4)$ & $10(83.3)$ & $14(73.7)$ & & $10(83.3)$ & $14(73.7)$ & & $5(100)$ & $19(73.1)$ & \\
\hline$\geq 3$ months and $<6$ months & $7(22.6)$ & $2(16.7)$ & $5(26.3)$ & & $2(16.7)$ & $5(26.3)$ & & $0(0)$ & $7(26.9)$ & \\
\hline $\begin{array}{l}\text { Dosage of apatinib, mean } \pm \\
\text { SD, } g\end{array}$ & $\begin{array}{l}69.86 \pm \\
41.38\end{array}$ & $\begin{array}{l}55.47 \pm \\
24.84\end{array}$ & $\begin{array}{l}78.95 \pm \\
47.46\end{array}$ & 0.049 & $\begin{array}{l}56.41 \pm \\
24.02\end{array}$ & $\begin{array}{l}78.36 \pm \\
48.00\end{array}$ & 0.034 & $\begin{array}{l}42.35 \pm \\
16.23\end{array}$ & $\begin{array}{l}75.15 \pm \\
42.81\end{array}$ & 0.096 \\
\hline
\end{tabular}

Abbreviations: $N$ number, VAT visceral adipose tissue, SAT subcutaneous adipose tissue, IMAT intermuscular adipose tissue, FIGO International Federation of Gynecology and Obstetrics, ECOG Eastern Cooperative Oncology Group, SD standard deviation, $g$ gram

*Fisher's exact tests

0.03-0.62, $P=0.011)$ decreased risk of death, high areas of VAT, SAT, and IMAT in patients with respectively.

platinum-resistant or platinum-refractory ovarian cancer who received apatinib-based therapy. High areas of VAT

\section{Discussion}

This secondary analysis of the AEROC trial demonand SAT predicted a better response to apatinib in this strated an association between improved outcomes and cohort. Moreover, PFS and OS were significantly superior in patients with high areas of VAT, SAT, and IMAT.

Table 2 Logistic regression analysis for AT associated with objective response rates

\begin{tabular}{|c|c|c|c|c|}
\hline \multirow[t]{2}{*}{ Variable } & \multicolumn{2}{|l|}{ Univariate } & \multicolumn{2}{|l|}{ Multivariate* } \\
\hline & Odds ratio $(95 \% \mathrm{Cl})$ & $P$ value & Odds ratio $(95 \% \mathrm{Cl})$ & $P$ value \\
\hline \multicolumn{5}{|l|}{ VAT } \\
\hline High versus low & $0.13(0.03-0.68)$ & 0.015 & $0.16(0.03-0.90)$ & 0.037 \\
\hline \multicolumn{5}{|l|}{ SAT } \\
\hline High versus low & $0.13(0.03-0.68)$ & 0.015 & $0.16(0.03-0.87)$ & 0.034 \\
\hline \multicolumn{5}{|l|}{ IMAT } \\
\hline High versus low & $0.11(0.01-1.16)$ & 0.066 & $0.18(0.02-2.04)$ & 0.166 \\
\hline
\end{tabular}



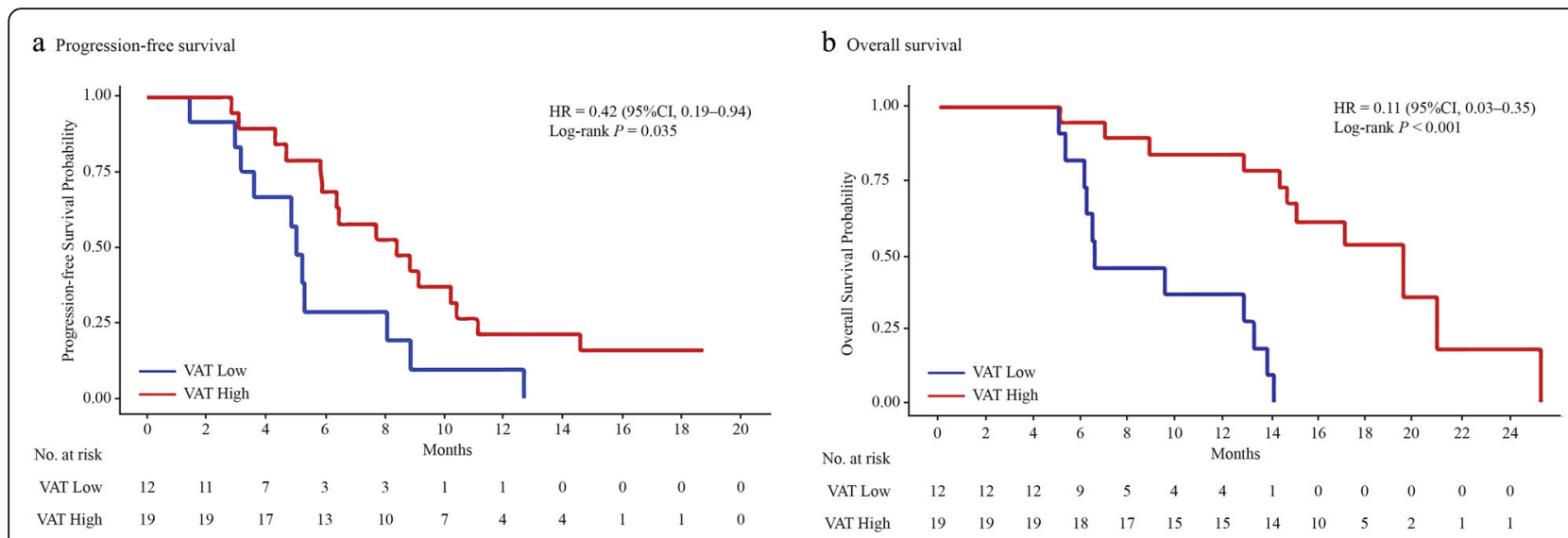

Fig. 2 The Kaplan-Meier curves showing a progression-free survival and $\mathbf{b}$ overall survival in patients with low VAT and high VAT. VAT, visceral adipose tissue

Although apatinib exposure was higher among patients with high VAT, high SAT, and high IMAT, the areas of VAT, SAT, and IMAT still remained significant predictors for outcome of patients treated with apatinib after controlling for apatinib exposure. To our knowledge, this is the first time that the predictive value of AT area has been evaluated in patients with platinum-resistant ovarian cancer who received VEGFR inhibitors.

There are currently only a few studies on the predictive value of AT area in patients receiving VEGF-targeted treatment. In 64 patients with metastatic renal cell carcinoma treated with VEGF-targeted therapy, a high area of VAT was independently associated with shorter time to progression (HR, 3.07; 95\% CI, 1.52-6.20; $P=0.002$ ) and OS (HR, 6.26; 95\% CI, 2.29-17.08; $P<0.001)$ [16]. In contrast, Steffens et al. [17] demonstrated that lower areas of VAT (HR, 3.26; 95\% CI, 1.36-7.62; $P=0.006$, and HR, 2.97; 95\% CI, 1.36-6.47; $P=0.006$, respectively) and SAT (HR, 2.66; 95\% CI, 1.24-5.69; $P=0.012$, and HR, 3.41; 95\% CI, $1.61-7.25 ; P=0.001$, respectively) predicted shorter PFS and OS in patients in the same setting. The observations in the current study were in line with the work of Steffens et al. and gave further support that high areas of VAT and SAT predicted better outcomes in patients treated with VEGFR inhibitors.

Despite extensive efforts, much remains to be learned about the predictive value of AT in patients receiving VEGF-targeted treatment. There is increasing evidence that AT does not simply store energy but is also an essential endocrine organ, secreting a large number of inflammatory cytokines, which is favorable for tumor development $[23,24]$. In particular, many cytokines produced by AT show angiogenic activities [13, 14]. This could explain why a large amount of AT is associated with high proangiogenic factor levels and therefore resistance to VEGF-targeted therapy $[15,16]$. However, the crosstalk between angiogenesis and adipogenesis is complex $[14,25]$. The consequences of modulation of angiogenic activity seem to be context-dependent. For instance, inhibition of VEGF-A in wild-type mice at the
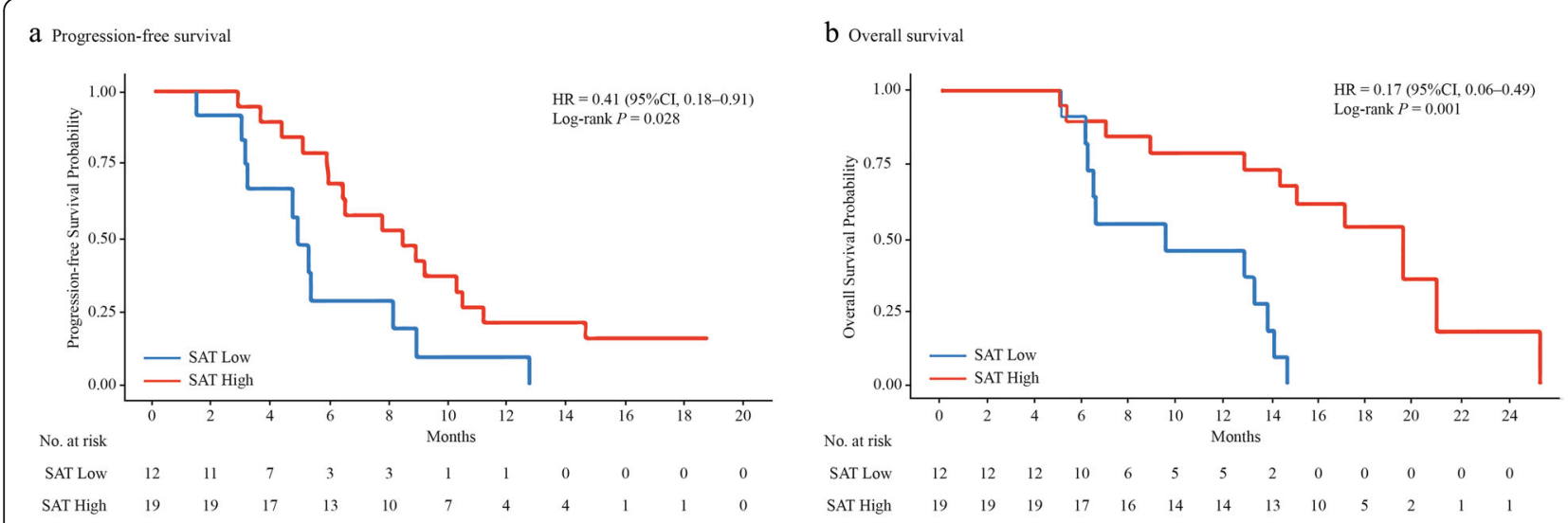

Fig. 3 The Kaplan-Meier curves showing a progression-free survival and $\mathbf{b}$ overall survival in patients with low SAT and high SAT. SAT, subcutaneous adipose tissue 

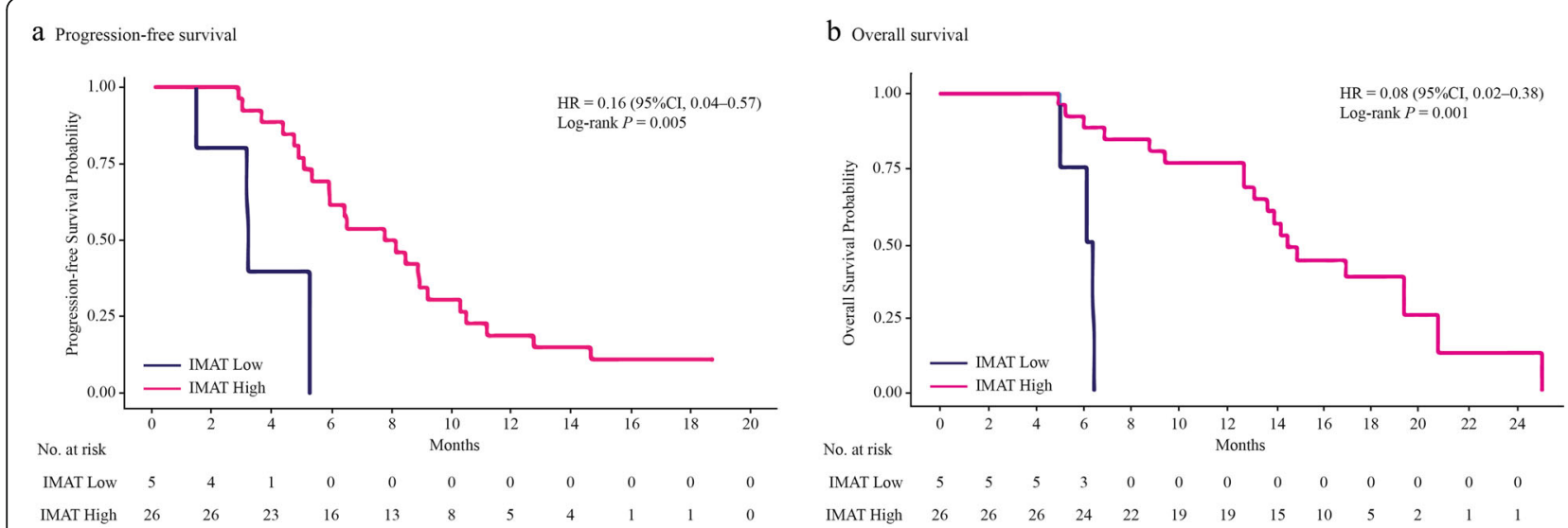

Fig. 4 The Kaplan-Meier curves showing a progression-free survival and $\mathbf{b}$ overall survival in patients with low IMAT and high IMAT. IMAT, intermuscular adipose tissue

initial stages of high-fat food feeding causes aggravated systemic insulin resistance [25], which has been linked to several types of cancer [26-28]. However, the same blockade in mice with preexisting AT dysfunction had the opposite effect, with an improvement in insulin sensitivity and a decrease in inflammatory factors [25]. These findings may be a plausible explanation for the contradictory results regarding the predictive value of AT for VEGF-targeted treatment [15-18], and to some extent support our hypothesis that anti-angiogenic therapy in patients cancer with high adipose depots, who have preexisting AT dysfunction, is more likely to result in the reduction of inflammatory cytokines, which may favor a better outcome.

Until now, the optimal cutoff for specific adipose depots has not been well defined. Both the median value [15-17] and various tertiles [20, 29] have been used as cutoffs for AT area. Optimum stratification, which is widely used for identifying the threshold value of a continuous covariate by log-rank statistics testing [30], was used in this study to identify the cutoffs for different adipose depots. It should be noted that the patient population in the current study was small, and it is theoretically difficult to obtain statistically significant results. Surprisingly, we found that patients with different outcomes were well separated by the cutoffs identified by optimum stratification. This may be partly attributable to the optimum stratification method used in our study. Another plausible explanation might be that the areas of VAT, SAT, and IMAT are robust predictors of good outcomes in this patient population. However, further studies are warranted to validate these findings.

The adipose organ includes numerous discrete anatomical depots. Emerging evidence indicates that not all AT depots carry equivalent risk for metabolic abnormalities [31, 32]. However, the contribution of different AT depots to the response to VEGF-targeted therapy is unknown [16, 17]. Steffens et al. [17] identified the areas of both VAT and SAT as positive predictive biomarkers for patients with metastatic renal cell carcinoma treated with VEGF-targeted therapy. However, in the study of Ladoire et al. [16], no significant association was observed between areas of SAT and time to progression or OS in the same setting. In the current study, we

Table 3 Multivariate analysis for AT associated with progression-free survival and overall survival

\begin{tabular}{|c|c|c|c|c|c|c|c|c|}
\hline \multirow[t]{3}{*}{ Variable } & \multicolumn{3}{|l|}{ Univariate } & \multicolumn{5}{|c|}{ Multivariate* } \\
\hline & \multicolumn{2}{|c|}{ Progression-free survival } & \multicolumn{2}{|l|}{ Overall survival } & \multicolumn{2}{|c|}{ Progression-free survival } & \multicolumn{2}{|l|}{ Overall survival } \\
\hline & HR $(95 \% \mathrm{Cl})$ & $P$ value & $\mathrm{HR}(95 \% \mathrm{Cl})$ & $P$ value & $\mathrm{HR}(95 \% \mathrm{Cl})$ & $P$ value & $\mathrm{HR}(95 \% \mathrm{Cl})$ & $P$ value \\
\hline \multicolumn{9}{|l|}{ VAT } \\
\hline High versus low & $0.42(0.19-0.94)$ & 0.035 & $0.11(0.03-0.35)$ & $<0.001$ & $0.39(0.17-0.92)$ & 0.031 & $0.12(0.04-0.40)$ & $<0.001$ \\
\hline \multicolumn{9}{|l|}{ SAT } \\
\hline High versus low & $0.41(0.18-0.91)$ & 0.028 & $0.17(0.06-0.49)$ & 0.001 & $0.35(0.15-0.83)$ & 0.027 & $0.24(0.08-0.67)$ & 0.007 \\
\hline \multicolumn{9}{|l|}{ IMAT } \\
\hline High versus low & $0.16(0.04-0.57)$ & 0.005 & $0.08(0.02-0.38)$ & 0.001 & $0.20(0.06-0.74)$ & 0.016 & $0.13(0.03-0.62)$ & 0.011 \\
\hline
\end{tabular}

Abbreviations: $A T$ adipose tissue, VAT visceral adipose tissue, SAT subcutaneous adipose tissue, IMAT intermuscular adipose tissue, $\mathrm{HR}$ hazard ratio, $\mathrm{Cl}$ confidence interval

${ }^{*}$ Adjusted for apatinib exposure 
demonstrated that all three adipose depots had a positive association with the outcome of patients receiving VEGF $\mathrm{R}$ inhibitors. To our knowledge, this is the first analysis to investigate the predictive value of IMAT for VEGFtargeted therapy. Interestingly, we further found that the largest reduction of risk of disease progression was observed in patients with high IMAT. Nevertheless, as IMAT is a novel and less well-studied AT depot, more data are needed to validate our findings.

We acknowledge that the patients in our study received oral etoposide as well which might to some extent contribute to the outcome of treatment. A growing body of evidence shows the existence of crosstalk between angiogenesis and adipogenesis [14, 33], providing the theoretical underpinnings of the association between AT area and outcome of treatment with apatinib. However, we could not show the difference in outcome for patients is purely attributable to the interaction of AT depots and apatinib.

\section{Limitations}

Our study has several limitations. First, the AEROC trial was prospective but the current analysis was post hoc. The AEROC trial was not originally powered to evaluate the predictive value of AT for the efficacy of apatinib treatment. In addition, we did not internally validate our findings due to the small sample size. Therefore, we are not aware of the extent to which our findings could be replicated in this setting. Second, the AEROC trial was a single-arm trial with a relatively small sample size, and selection bias may affect the generalizability of the results.

\section{Conclusions}

In this secondary analysis of the AEROC trial, high areas of VAT, SAT, and IMAT were significantly associated with better outcomes in patients with platinum-resistant ovarian cancer who received VEGFR inhibitor treatment. AT assessments may be valuable as patient-specific imaging biomarkers for predicting response to VEGFR inhibitor treatment and help individualize the treatment of patients with platinum-resistant ovarian cancer.

\section{Supplementary information}

Supplementary information accompanies this paper at https://doi.org/10. 1186/s12916-020-01733-4.

Additional file 1: Table S1. Best cutoffs for the areas of VAT associated with the objective response rate. Table S1 showed the performance of the proposed cutoffs selected by the SAS \%cutpoint macro. The cutoff 33 $\mathrm{cm}^{2}$ achieved the highest total score. However, an area of $55.53 \mathrm{~cm}^{2}$ was selected instead of $33 \mathrm{~cm}^{2}$ as the optimal cutoff because it was not only significantly associated with objective response rate but also associated with progression-free survival and overall survival. VAT: visceral adipose tissue; Cl, confidence interval.
Additional file 2: Fig. S1. Plot of cutoff selection for the area of VAT associated with progression-free survival. The $x$-axis represents the area of VAT and the $y$-axis shows the Wald $P$ value. The horizontal dotted gray line indicates significance. Points above the line have a $P>0.05$, and points below the line have a $P<0.05$ and are suitable as cutoffs. VAT: visceral adipose tissue.

Additional file 3: Fig. S2. Plot of cutoff selection for the area of VAT associated with overall survival. The $x$-axis represents the area of VAT and the $y$-axis shows the Wald $P$ value. The horizontal dotted gray line indicates significance. Points above the line have a $P>0.05$, and points below the line have a $P<0.05$ and are suitable as cutoffs. VAT: visceral adipose tissue.

Additional file 4: Table S2. Best cutoffs for the areas of SAT associated with the objective response rate. Table $\$ 2$ showed the performance of the proposed cutoffs selected by the SAS \%cutpoint macro. Although the area of $110 \mathrm{~cm}^{2}$ achieved the highest total score, the area of $129.28 \mathrm{~cm}^{2}$ was selected as the optimal cutoff because it was significantly associated with objective response rate as well as progression-free survival and overall survival. SAT: subcutaneous adipose tissue; Cl: confidence interval.

Additional file 5: Fig. S3. Plot of cutoff selection for the area of SAT associated with progression-free survival. The $x$-axis represents the area of SAT and the $y$-axis shows the Wald $P$ value. The horizontal dotted gray line indicates significance. Points above the line have a $P>0.05$, and points below the line have a $P<0.05$ and are suitable as cutoffs. SAT: subcutaneous adipose tissue.

Additional file 6: Fig. S4. Plot of cutoff selection for the area of SAT associated with overall survival. The $x$-axis represents the area of SAT and the $y$-axis shows the Wald $P$ value. The horizontal dotted gray line indicates significance. Points above the line have a $P>0.05$, and points below the line have a $P<0.05$ and are suitable as cutoffs. SAT: subcutaneous adipose tissue.

Additional file 7: Table S3. Best cutoffs for the areas of IMAT associated with the objective response rate. Table S3 showed the performance of the proposed cutoffs selected by the SAS \%cutpoint macro. The cutoff $5 \mathrm{~cm} 2$ had the highest total score. However, an area of $3.28 \mathrm{~cm}^{2}$ was selected instead of $5 \mathrm{~cm}^{2}$ as the optimal cutoff because it was not only significantly associated with objective response rate but also associated with progression-free survival and overall survival. IMAT: intermuscular adipose tissue; $\mathrm{Cl}$ : confidence interval.

Additional file 8: Fig. S5. Plot of cutoff selection for the area of IMAT associated with progression-free survival. The $\mathrm{x}$-axis represents the area of IMAT and the $y$-axis shows the Wald P value. The horizontal dotted gray line indicates significance. Points above the line have a $P>0.05$, and points below the line have a $\mathrm{P}<0.05$ and are suitable as cutoffs. IMAT: intermuscular adipose tissue.

Additional file 9: Fig. S6. Plot of cutoff selection for the area of IMAT associated with overall survival. The $x$-axis represents the area of IMAT and the $y$-axis shows the Wald $P$ value. The horizontal dotted gray line indicates significance. Points above the line have a $P>0.05$, and points below the line have a $\mathrm{P}<0.05$ and are suitable for selection as cutoffs. IMAT: intermuscular adipose tissue.

Additional file 10: Fig. S7. Representative $C T$ images for patients with high and low AT areas. (A) to (D): CT images for patients with high AT areas, (A) the original $C T$ image of $A T$ and the segmentation of (B) VAT, (C) SAT, and (D) IMAT. (E) to (H): CT images for patients with low AT areas, $(E)$ the original $C T$ image of AT and the segmentation of (F) VAT, (G) SAT, and (H) IMAT.

Additional file 11: Study protocol.

\section{Abbreviations}

VEGF: Vascular endothelial growth factor; VEGFR: VEGF receptor; TKI: Tyrosine kinase inhibitor; PFS: Progression-free survival; AT: Adipose tissue; FGF2: Fibroblast growth factor-2; TGF- $\beta$ : Tumor growth factor $\beta$; PGF: Placental growth factor; VAT: Visceral AT; SAT: Subcutaneous AT; CT: Computed tomography; IMAT: Intermuscular AT; ORR: Objective response rate; RECI ST: Response Evaluation Criteria In Solid Tumors; OS: Overall survival; HU: Hounsfield units; HR: Hazard ratio; Cl: Confidence interval 


\section{Acknowledgements}

The authors thank Professor Haiqiang Mai, Sun Yat-sen University Cancer Centre, for his valuable comments and suggestions to this manuscript.

\section{Authors' contributions}

Study concept and design: Xia and Lan. Acquisition, analysis, or interpretation of data: Huang, Xie, Tang, He, F. Yang, Tian, Li, Q. Yang, Shen, Xia, and Lan. Statistical analysis: Xie, He, F. Yang, and Lan. Drafting of the manuscript: He and Lan. Critical revision for important intellectual content: Huang, Tang, F. Yang, and Xia. Final approval of manuscript: all authors read and approved the final manuscript. Supervision: Huang, He, Tang, Xia, and Lan.

\section{Funding}

This study was supported by grants from the National Natural Science Foundation of China (No. 81702754), the Science and Technology Project of Guangdong Province (2016A030313849), and the Guangdong Medical Science and Technology Research Fund (C2018063). The funding sources had no role in the design and conduct of the study; collection management, analysis, and interpretation of the data; preparation, review, or approval of the manuscript; and decision to submit the manuscript for publication.

\section{Availability of data and materials}

The key raw data have been recorded at Research Data Deposit public platform (http://www.researchdata.org.cn) with number RDDA2019001126. The data are available from Research Data Deposit, but restrictions apply to the availability of these data, which were used under license for the current study, and so are not publicly available. Data are however available from the authors upon reasonable request and with permission of Research Data Deposit public platform.

\section{Ethics approval and consent to participate}

Informed consent was obtained from all patients. Ethical approval was obtained by the institutional review board of Sun Yat-sen University Cancer Centre (B2016-020-03). The procedures were in accordance with the ethical standards.

\section{Consent for publication}

Not applicable

\section{Competing interests}

The authors declare that they have no competing interests.

\section{Author details}

${ }^{1}$ Department of Gynecologic Oncology, Sun Yat-sen University Cancer Centre, State Key Laboratory of Oncology in South China, Collaborative Innovation Center for Cancer Medicine, 651 Dongfeng Road East, Guangzhou 510060, Guangdong, China. ${ }^{2}$ Department of Cancer Prevention, Sun Yat-sen University Cancer Centre, State Key Laboratory of Oncology in South China, Collaborative Innovation Center for Cancer Medicine, Guangzhou, China. ${ }^{3}$ Department of Gynecologic Oncology, Hunan Cancer Hospital, the Affiliated Cancer Hospital of Xiangya School of Medicine, Central South University, Changsha, China. ${ }^{4}$ VIP Region, Sun Yat-sen University Cancer Centre, State Key Laboratory of Oncology in South China, Collaborative Innovation Center for Cancer Medicine, 651 Dongfeng Road East, Guangzhou 510060, Guangdong, China. ${ }^{5}$ Department of Medical Imaging, Sun Yat-sen University Cancer Centre, State Key Laboratory of Oncology in South China, Collaborative Innovation Center for Cancer Medicine, Guangzhou, China.

\section{Received: 5 April 2020 Accepted: 5 August 2020}

Published online: 05 October 2020

\section{References}

1. Siegel RL, Miller KD, Jemal A. Cancer statistics, 2018. CA Cancer J Clin. 2018; 68:7-30 https://doi.org/10.3322/caac.21442.

2. Byrne AT, Ross L, Holash J, Nakanishi M, Hu L, Hofmann Jl, et al. Vascular endothelial growth factor-trap decreases tumor burden, inhibits ascites, and causes dramatic vascular remodeling in an ovarian cancer model. Clin Cancer Res. 2003;9:5721-8.
3. Monk BJ, Minion LE, Coleman RL. Anti-angiogenic agents in ovarian cancer: past, present, and future. Ann Oncol. 2016;27(Suppl1):i33-9 https://doi.org/ 10.1093/annonc/mdw093.

4. Burger RA, Brady MF, Bookman MA, Fleming GF, Monk BJ, Huang H, et al. Incorporation of bevacizumab in the primary treatment of ovarian cancer. $N$ Engl J Med. 2011;365:2473-83 https://doi.org/10.1056/NEJMoa1104390.

5. Perren TJ, Swart AM, Pfisterer J, Ledermann JA, Pujade-Lauraine E, Kristensen $\mathrm{G}$, et al. A phase 3 trial of bevacizumab in ovarian cancer. N Engl J Med. 2011;365:2484-96 https://doi.org/10.1056/NEJMoa1103799.

6. Bianchini $F$, Kaaks $\mathrm{R}$, Vainio $\mathrm{H}$. Overweight, obesity, and cancer risk. Lancet Oncol. 2002;3:565-74 https://doi.org/10.1016/s1470-2045(02)00849-5.

7. Arem H, Irwin ML. Obesity and endometrial cancer survival: a systematic review. Int J Obes. 2013;37:634-9. https://doi.org/10.1038/ijo.2012.94.

8. Calle EE, Rodriguez C, Walker KA, Wingo PA, Petrelli JM, Thun MJ. Tubal sterilization and risk of breast cancer mortality in US women. Cancer Causes Control. 2001;12:127-35 https://doi.org/10.1023/a:1008914209146.

9. Yoon HH, Lewis MA, Shi Q, Khan M, Cassivi SD, Diasio RB, et al. Prognostic impact of body mass index stratified by smoking status in patients with esophageal adenocarcinoma. J Clin Oncol. 2011;29:4561-7 https://doi.org/ 10.1200/JCO.2011.37.1260.

10. Hursting SD, Dunlap SM. Obesity, metabolic dysregulation, and cancer: a growing concern and an inflammatory (and microenvironmental) issue. Ann N Y Acad Sci. 2012;1271:82-7 https://doi.org/10.1111/j.1749-6632.2012. 06737.x.

11. Aggarwal BB, Gehlot P. Inflammation and cancer: how friendly is the relationship for cancer patients? Curr Opin Pharmacol. 2009;9:351-69 https://doi.org/10.1016/j.coph.2009.06.020.

12. Ferrara N, Kerbel RS. Angiogenesis as a therapeutic target. Nature. 2005;438: 967-74 https://doi.org/10.1038/nature04483.

13. Gómez-Ambrosi J, Catalán V, Rodríguez A, Ramírez B, Silva C, Gil MJ, et al. Involvement of serum vascular endothelial growth factor family members in the development of obesity in mice and humans. J Nutr Biochem. 2010;21: 774-80 https://doi.org/10.1016/j.jnutbio.2009.05.004.

14. Cao Y. Angiogenesis modulates adipogenesis and obesity. J Clin Invest. 2007;117:2362-8 https://doi.org/10.1172/JCl32239.

15. Guiu B, Petit JM, Bonnetain F, Ladoire S, Guiu S, Cercueil JP, et al. Visceral fat area is an independent predictive biomarker of outcome after first-line bevacizumab-based treatment in metastatic colorectal cancer. Gut. 2010;59: 341-7 https://doi.org/10.1136/gut.2009.188946.

16. Ladoire S, Bonnetain F, Gauthier M, Zanetta S, Petit JM, Guiu S, et al. Visceral fat area as a new independent predictive factor of survival in patients with metastatic renal cell carcinoma treated with antiangiogenic agents. Oncologist. 2011;16:71-81 https://doi.org/10.1634/theoncologist.2010-0227.

17. Steffens S, Grünwald V, Ringe Kl, Seidel C, Eggers H, Schrader M, et al. Does obesity influence the prognosis of metastatic renal cell carcinoma in patients treated with vascular endothelial growth factor-targeted therapy? Oncologist. 2011;16:1565-71 https://doi.org/10.1634/theoncologist.20110213.

18. Grignol VP, Smith AD, Shlapak D, Zhang X, Del Campo SM, Carson WE. Increased visceral to subcutaneous fat ratio is associated with decreased overall survival in patients with metastatic melanoma receiving antiangiogenic therapy. Surg Oncol. 2015;24:353-8 https://doi.org/10.1016/j. suronc.2015.09.002.

19. Lan CY, Wang Y, Xiong Y, Li JD, Shen JX, Li YF, et al. Apatinib combined with oral etoposide in patients with platinum-resistant or platinumrefractory ovarian cancer (AEROC): a phase 2, single-arm, prospective study. Lancet Oncol. 2018;19:1239-46 https://doi.org/10.1016/S14702045(18)30349-8.

20. Lee J, Chang CL, Lin JB, Wu MH, Sun FJ, Jan YT, et al. Skeletal muscle loss is an imaging biomarker of outcome after definitive chemoradiotherapy for locally advanced cervical cancer. Clin Cancer Res. 2018;24:5028-36 https:// doi.org/10.1158/1078-0432.CCR-18-0788.

21. van Dijk DP, Bakens MJ, Coolsen MM, Rensen SS, van Dam RM, Bours MJ, et al. Low skeletal muscle radiation attenuation and visceral adiposity are associated with overall survival and surgical site infections in patients with pancreatic cancer. J Cachexia Sarcopenia Muscle. 2017;8:317-26. https://doi. org/10.1002/jcsm.12155 Epub 2016 Oct 26.

22. Williams BA, Mandrekar JN, Mandrekar SJ, Cha SS, Furth AF. Finding optimal cutpoints for continuous covariates with binary and time-to-event outcomes. In: Rochester, MN, editor. Mayo Foundation Technical Report Series. Mayo Clinic: 2006. p. 79. 
23. Xu H, Barnes GT, Yang Q, Tan G, Yang D, Chou CJ, et al. Chronic inflammation in fat plays a crucial role in the development of obesityrelated insulin resistance. J Clin Invest. 2003;112:1821-30 https://doi.org/10. 1172/JCI19451.

24. Catalán V, Gómez-Ambrosi J, Rodríguez A, Ramírez B, Silva C, Rotellar F, et al. Up-regulation of the novel proinflammatory adipokines lipocalin-2, chitinase-3 like-1 and osteopontin as well as angiogenic-related factors in visceral adipose tissue of patients with colon cancer. J Nutr Biochem. 2011; 22:634-41 https://doi.org/10.1016/j.jnutbio.2010.04.015.

25. Sun K, Wernstedt Asterholm I, Kusminski CM, Bueno AC, Wang ZV, Pollard JW, et al. Dichotomous effects of VEGF-A on adipose tissue dysfunction. Proc Natl Acad Sci U S A. 2012;109:5874-9 https://doi.org/10.1073/pnas. 1200447109.

26. Giovannucci E. Insulin and colon cancer. Cancer Causes Control. 1995;6:16479 https://doi.org/10.1007/bf00052777.

27. Kaaks R. Nutrition, hormones, and breast cancer: is insulin the missing link? Cancer Causes Control. 1996;7:605-25 https://doi.org/10.1007/bf00051703.

28. Kaaks R, Lukanova A, Kurzer MS. Obesity, endogenous hormones, and endometrial cancer risk: a synthetic review. Cancer Epidemiol Biomark Prev. 2002;11:1531-43.

29. Caan BJ, Cespedes Feliciano EM, Prado CM, Alexeeff S, Kroenke CH, Bradshaw $\mathrm{P}$, et al. Association of muscle and adiposity measured by computed tomography with survival in patients with nonmetastatic breast cancer. JAMA Oncol. 2018:4:798-804 https://doi.org/10.1001/jamaoncol. 2018.0137.

30. Prado $C M$, Lieffers JR, McCargar $L$, Reiman $T$, Sawyer $M B$, Martin $L$, et al. Prevalence and clinical implications of sarcopenic obesity in patients with solid tumours of the respiratory and gastrointestinal tracts: a populationbased study. Lancet Oncol. 2008;9:629-35 https://doi.org/10.1016/S14702045(08)70153-0.

31. Kissebah AH, Vydelingum N, Murray R, Evans DJ, Hartz AJ, Kalkhoff RK, et al. Relation of body fat distribution to metabolic complications of obesity. J Clin Endocrinol Metab. 1982;54:254-60 https://doi.org/10.1210/jcem-54-2254.

32. Rexrode KM, Carey VJ, Hennekens CH, Walters EE, Colditz GA, Stampfer MJ et al. Abdominal adiposity and coronary heart disease in women. JAMA. 1998:280:1843-8 https://doi.org/10.1001/jama.280.21.1843.

33. Dallabrida SM, Zurakowski D, Shih SC, Smith LE, Folkman J, Moulton KS, et al. Adipose tissue growth and regression are regulated by angiopoietin-1. Biochem Biophys Res Commun. 2003;311:563-71. https://doi.org/10.1016/j. bbrc.2003.10.007.

\section{Publisher's Note}

Springer Nature remains neutral with regard to jurisdictional claims in published maps and institutional affiliations.

Ready to submit your research? Choose BMC and benefit from:

- fast, convenient online submission

- thorough peer review by experienced researchers in your field

- rapid publication on acceptance

- support for research data, including large and complex data types

- gold Open Access which fosters wider collaboration and increased citations

- maximum visibility for your research: over $100 \mathrm{M}$ website views per year

At $\mathrm{BMC}$, research is always in progress.

Learn more biomedcentral.com/submissions 